Referencia para citar este artículo: Rezende, H. N., \& Bianchi, A. (2019). Adaptação Brasileira da Escala Clima Familiar para Segurança no Trânsito. Revista Latinoamericana de Ciencias Sociales, Niñez y Juventud, 17(1), 223-236. doi:https://dx.doi.org/10.11600/1692715x.17113

\title{
Adaptação Brasileira da Escala Clima Familiar para Segurança no Trânsito*
}

\author{
Hugo NASCIMENTo REZENDE** \\ Mestrando Universidade Federal do Paraná, Brasil. \\ Alessandra SANT'ANNA BIANCHI *** \\ Professora Universidade Federal do Paraná, Brasil.
}

\section{Artículo recibido en septiembre 27 de 2017; artículo aceptado en febrero 25 de 2018 (Eds.)}

- Resumo (analítico): esta pesquisa visa verificar evidências de validade da adaptação brasileira da Escala Clima Familiar para Segurança no Trânsito (Taubman-Ben-Ari \& Katz-BenAmi, 2013), que avalia a percepção de jovens condutores sobre valores, prioridades, e práticas dos pais e da família em relação à condução segura. Participaram da pesquisa 420 universitários (63\% homens), com idade entre 18 e 22 anos (média=19,7 anos; $D P=1,3$ anos). A análise fatorial indicou uma solução de cinco fatores: Comunicação/Mensagem $(\alpha=0,87)$, Monitoramento/Limites $(\alpha=0,87)$, Falta de Compromisso com a Segurança $(\alpha=0,70)$, Modelagem $(\alpha=0,79)$ e Feedback $(\alpha=0,80)$. Os dados mostram que a versão brasileira da escala apresentou resultados adequados e pode ser utilizada em estudos futuros sobre clima familiar em relação à condução.

Palavras chave autores: clima familiar, jovem condutor, mobilidade.

\section{Brazilian adaptation of the Family Climate Scale for Road Safety}

- Abstract (analytical): This research has the objective of verifying the evidence of the validity of the Brazilian version of the Family Climate Scale for Road Safety (Taubman-Ben-Ari \& Katz-BenAmi, 2013), which evaluates the perception of young drivers of their values and priorities and the practices of parents and relatives in relation to safe driving. The participants were 420 university students (63\% men) aged between 18 and 22 (mean $=19.7$ years, $S D=1.3$ years). Factor analysis indicated a five-factor solution: Communication / Message $(\alpha=0.87)$, Monitoring / Limits $(\alpha=0.87)$, Lack of Commitment to Safety $(\alpha=0.70)$, Modeling $(\alpha=0.79)$ and Feedback $(\alpha=0.80)$. The data show that the Brazilian version of the scale achieved suitable results and can be used in future studies of family environments in relation to driving.

Key words authors: Family climate, young drivers, movility.

Este artigo de pesquisa científica e tecnológica procede da pesquisa: Adaptação Brasileira da Escala Clima Familiar para Segurança no Trânsito, desenvolvida no período de Abril de 2013 a Agosto de 2015, sob financiamento da Coordenação de Aperfeiçoamento de Pessoal de Nível Superior (Capes). O número de aprovação do Comitê de Ética em pesquisa do Universidade Federal do Paraná e 1205 116. Área: psicologia; sub-área: psicologia social.

** Mestre em Psicologia da Universidade Federal do Paraná. Psicólogo da Secretaria de Transporte e Trânsito de São José dos Pinhais, Paraná. Brasil. Orcid: 0000-0003-2689-8448. E-mail: hnrezende@gmail.com

*** $\quad$ Doutora em Psicologia pela Universidad de Barcelona-Espanha. Professora associada na Universidade Federal do Paraná. Brasil. Orcid: 00000003-3937-4520. Índice H5: 3. E-mail: bianchi@ufpr.br 


\section{Adaptación brasileña de la Escala Clima Familiar para la seguridad vial}

- Resumen (analítico): esta investigación tiene como objetivo buscar evidencias de la validez de la versión brasileña de la Escala Clima Familiar para la Seguridad Vial (Taubman Ben-Ari y Katz-Bien-Ami, 2013), la cual evalúa la percepción de los conductores jóvenes sobre los valores, las prioridades y las prácticas de sus padres y de la familia con respecto a la conducción segura. Los participantes fueron 420 estudiantes universitarios (63\% hombres) con edades comprendidas entre 18 y 22 años (media=19,7 años, $D S=1,3$ años). El análisis factorial indicó una solución en cinco factores: Comunicación/Mensaje $(\alpha=0,87)$, Monitoreo/Limites $(\alpha=0,87)$, Falta de Compromiso con la Seguridad $(\alpha=0,70)$, el Modelado $(\alpha=0,79)$ y Feedback $(\alpha=0,80)$. Los datos indican que la versión brasileña de la Escala Clima Familiar para la Seguridad Vial es adecuada y puede ser utilizada en futuros estudios que quieran evaluar el impacto del ambiente familiar en la formación de los conductores jóvenes.

Palabras clave autores: clima familiar, joven conductor, movilidad.

-1. Introdução. -2. Método. -2.1 Participantes da Pesquisa -2.2. Instrumentos. -2.3. Procedimento Coleta de Dados. -2.4. Procedimento Análise de dados. -3. Resultados. -4 Discussão. -5 Limitações do Estudo. -6. Considerações Finais. -Referências.

\section{Introdução}

Os acidentes de trânsito são as causas mais comuns de mortes entre jovens de 15 a 29 anos. Eles constituem um sério problema de saúde pública causador de mortes e sofrimentos para a população. (W. H. O., 2013)

Os dados apresentados pela World Health Organization (2013) e no relatório anual do Departamento de Trânsito do Paraná (2010) explanam acerca de acidentes com mortes e sequelas, bem como das infrações no trânsito que tornam-se um problema de saúde pública, em especial em condutores com idade de 18 a 25 anos. Entretanto, faz-se necessário pesquisar possíveis fatores que possam estar na gênese destes resultados. Assim, o presente estudo busca preencher algumas lacunas buscando compreender a influência dos pais/familiares no início da vida dos filhos no trânsito, como condutores.

No Brasil o Estatuto da Criança e do Adolescente - ECA — (Brasil, 1990), instituído pela lei n ${ }^{\circ}$ $8.069 / 90$, em seu artigo $4^{\circ}$ destaca que

É dever da família, da comunidade, da sociedade em geral e do poder público assegurar, com absoluta prioridade, a efetivação dos direitos referentes à vida, à saúde, à alimentação, à educação, ao esporte, ao lazer, à profissionalização, à dignidade, ao respeito, à liberdade e à convivência familiar e comunitária. (Brasil, 1990)

A família tem influência na educação, socialização, cuidados, transmissão de crenças e valores e no bem estar de seus componentes (Braconnier \& Marcelli, 2000). Bowen (1978) afirma que aspectos emocionais são transferidos de geração a geração. O conjunto de atitudes em relação à criança, comunicadas para a criança, por meio dos comportamentos dos pais é definido como estilo parental (Darling \& Steinberg, 1993).

Conforme Newman, Harrison, Dashiff e Davies (2008), a influência do estilo parental no desenvolvimento do adolescente é clara. Baumrind (1966) classificou três tipos de estilos parentais: autoritário, permissivo e autoritativo. Maccoby e Martin (1983) dividiram o estilo permissivo em dois: indulgente e negligente, com base em escalas de exigência e responsividade que são dimensões das práticas parentais. De acordo com Costa, Teixeira e Gomes (2000), responsividade são as atitudes compreensivas dos pais, que geram auto-afirmação, apoio e incentivo para que os filhos se tornem autônomos. Exigência é o meio pelo qual os pais buscam controlar o comportamento de seus filhos, através de regras e limites (Costa et al., 2000). Assim, pais indulgentes têm alta responsividade e baixa 
exigência; pais negligentes possuem baixa responsividade e baixa exigência e pais autoritários são altamente exigentes e pouco responsivos. Maccoby e Martin (1983) concluem que o estilo autoritativo seria o ideal, pois combina fatores como alta exigência e alta responsividade. Na área da psicologia do trânsito, o estudo de Cardoso (2009) mostrou que filhos de pais autoritativos se destacam por cometerem menos erros, lapsos, infrações agressivas e principalmente infrações ordinárias que filhos de pais negligentes.

$\mathrm{O}$ processo de dirigir é considerado um rito de passagem da adolescência à vida adulta e uma oportunidade de independência dos filhos (Morton \& Hartos, 2003). De acordo com Elander, West e French (1993) o estilo de condução é influenciado pelas atitudes e crenças que o sujeito possui sobre a condução. Taubman-Ben-Ari e Miller (2010) destacam que, um fator a ser considerado, no estilo de condução, é a influência dos pais.

Prato, Toledo, Lotan e Taubman-Ben-Ari (2010), destacam que a quantidade de supervisão e monitoramento dos pais influência positivamente na prática de condução dos filhos. (Prato et. al., 2010). Além da fiscalização e controle, existem outros fatores que estão por traz da relação pais e filhos no trânsito, como por exemplo a modelagem do comportamento de condução, ensino de habilidades e a comunicação entre eles (Goodwin, Foss, Margolis, \& Harrell, 2014; Schmidt, Morrongiello, \& Colwell, 2014).

Diversos estudos apresentam uma correlação significativa entre o estilo de condução dos pais e dos filhos (Ehsani, Simons-Morton, Xie, Klauer, \& Albert, 2014; Parker, Watson, King, \& Hyde, 2014; Taubman-Ben-Ari, Mikulincer, \& Gillath, 2005).

De acordo com Bianchi e Summala (2004) existem correlações positivas entre os erros de direção e infrações de trânsito de pais e filhos, possivelmente porque os pais transmitem intergeracionalmente o seu estilo de condução, que reflete tanto cognitivamente quanto em fatores motivacionais no futuro condutor. Os pais podem, em princípio, transmitir o seu estilo de condução através de predisposição genética (temperamento, agressividade, estilo cognitivo, atenção) e/ou pelo aprendizado dos modelos, que pode começar muito cedo quando as crianças observam seus pais na direção (Bianchi \& Summala, 2004).

Olson, Partner e Lavee (1985), destacam que não são apenas os estilos parentais que influenciam na postura do jovem condutor, mas também a dinâmica familiar. Para que exista uma boa dinâmica familiar faz-se necessária uma boa coesão. Coesão familiar é o vínculo emocional que membros da família possuem um com o outro, e a capacidade de adaptação destes membros em mudar uma resposta a estímulos diferentes, negociando com seus pares sem ferir as regras de relacionamento (Olson et al., 1985; Seligman \& Darling, 1997). De acordo com Taubman-Ben-Ari e Katz-BenAmi (2013) as famílias funcionais, nas quais os seus membros trabalham em conjunto no intuito de melhorar os relacionamentos e enfrentarem os seus problemas, tendem a ser mais ajustadas durante 0 ciclo de vida, conseguindo desenvolver suas atividades com mais estabilidade, ao passo que sistemas familiares disfuncionais demonstram pouca participação na vida de cada um de seus membros, separação e independência entre eles e dificuldade de apoiar um ao outro na resolução de problemas.

Conforme, Scott-Parker, Watson, King e Hyde (2012), os pais influenciam significativamente nas experiências e comportamentos de seus filhos no processo de direção. Eles fornecem um modelo para o comportamento de direção, tanto antes como depois de seus filhos começarem a dirigir (ScottParker et al., 2012). Simons-Morton e Quimet (2006) afirmam que quando os pais supervisionam os jovens condutores, tendem a colocá-los em situações difíceis, porém seguras, na condução do veículo, no intuito de alertá-los aos prováveis riscos que possam se envolver. Os pais durante a prática da condução supervisionada procuram criar um ambiente livre de distrações, como a não permissão de equipamentos eletrônicos (Simons-Morton \& Quimet, 2006). Assim, a prática supervisionada é muito mais segura, pois a condução independente permite que os jovens condutores lidem com situações complexas do cotidiano, por vezes na companhia de outros amigos com idade similares e utilizandose de dispositivos eletrônicos (Mayhew, Simpson, \& Pak, 2003). 
Beck, Shattuck e Raleigh (2001), descrevem que adolescentes que relatam possuir maior monitoramento e restrições pelos pais, apresentam um comportamento de não exceder o excesso de velocidade, bem como utilizar o cinto de segurança. Estes adolescentes possuem uma maior possibilidade de realizar ultrapassagens seguras e conscientes, dirigir na velocidade permitida da via, utilizar o cinto de segurança e não cometer infrações de trânsito (Beck et al., 2001). SimonsMorton e Quimet (2006) concluíram que direção perigosa, infrações de trânsito e acidentes, são menores entre os adolescentes cujos pais estabelecem limites e privilégios no início da condução. Curry, Corinne e Cara (2015), destacam que os pais mais comprometidos, que definem limites comportamentais adequados e evitam disciplinas rígidas, afetam positivamente no desenvolvimento de um comportamento saudável no trânsito. Por outro lado, jovens condutores que percebem que seus pais estão descompromissados com a segurança relatam ter uma condução mais imprudente e menos comprometida com a própria segurança (Curry et al., 2015).

Assim, com o intuito de avaliar a percepção de jovens condutores quanto aos valores, prioridades, e as práticas dos pais e da família em relação à condução segura, Taubman-Ben-Ari e Katz-Ben-Ami (2013) propõem a escala Family Climate for Road Safety (FCRS). É composta por sete subescalas: (1) Modelagem, (2) Feedback; (3) Comunicação, (4) Monitoramento, (5) Falta de Compromisso com a Segurança, (6) Mensagens e (7) Limites (Taubman-Ben-Ari Katz-Ben-Ami, (2013). Conforme Taubman-Bem-Ari (2015) os jovens condutores que possuem pais que são bons modelos, que possuem comunicação mais aberta, transmitem mensagens claras sobre direção segura, dão feedback, capacitam para uma condução segura, monitoram a condução, tendem a correr riscos com menos frequência, a serem mais comprometidos com a segurança e dirigir de forma menos agressiva e arriscada (Taubman-Ben-Ari, 2015). Este comportamento na relação familiar, favorece e incentiva a direção segura por parte dos jovens condutores (Taubman-Ben-Ari \& Katz-Ben-Ami, 2013).

A literatura indica que os pais influenciam no comportamento dos filhos no trânsito e propõe algumas formas de interpretar isso (Bianchi \& Sumala, 2004; Taubman-Bem-Ari, 2015). Assim, o objetivo geral deste trabalho é verificar evidências de validade da adaptação brasileira da Escala Clima Familiar para Segurança no Trânsito, proposta originalmente no estudo de Taubman-Ben-Ari \& Katz-Ben-Ami (2013), que avalia a percepção dos jovens condutores dos valores, prioridades, e as práticas dos pais e da família em relação à condução segura; bem como estudar se há diferenças nas subescalas propostas conforme sexo, com quem aprendeu a dirigir e com quem reside.

\section{Método}

\subsection{Participantes da Pesquisa}

Participaram da pesquisa 420 estudantes universitários (63\% homens), residentes na região da Grande Curitiba com idade entre 18 e 22 anos (Média=19,7 anos; DP=1,3 anos). Foi optado utilizar este número de participantes, baseando-se na amostra do estudo original, proposto por Taubman-BenAri \& Katz-Ben-Ami (2012). Quando questionados com quem vivem, 57,2\% informaram que residem com os pais, $13,2 \%$ residem apenas com a mãe, $12,9 \%$ residem sozinhos, $6,2 \%$ com familiares, $6 \%$ com amigos, $3,8 \%$ com cônjuges e $0,7 \%$ somente com o pai.

O tempo de Carteira Nacional de Habilitação variou de 12 a 60 meses (Média=16,3 meses, $\mathrm{DP}=13,4$ meses). Os participantes possuem Carteira Nacional de Habilitação categoria «A» (22,8\%), categoria «B» $(76,2 \%)$ ou categoria «AB» $(1 \%)$. Destaca-se que $54,9 \%$ dos participantes da pesquisa informaram que já tinham dirigido sem possuir Carteira Nacional de Habilitação.

Quando questionados com quem aprenderam a dirigir $36,4 \%$ informaram que foi com o pai, $8,4 \%$ com a mãe, $7,9 \%$ com outro familiar ou sozinho e $47,3 \%$ com o instrutor de autoescola. Quanto ao veículo que dirige $54,3 \%$ informaram que dirigem o veículo dos pais, $16,2 \%$ informaram que dirigem veículo dos pais, mas para uso próprio, $24,8 \%$ informaram que dirigem veículo próprio, 3,7\% dirigem veículo de familiares e 1\% veículo de outras pessoas (amigo/a ou cônjuge). 
Quando questionados quantos quilômetros dirigem por mês, 63,1\% informaram que dirigem de 2 a 2.000 quilômetros por mês (Média $=301,7 \mathrm{~km}, \mathrm{DP}=389,16$ ) e os $36,9 \%$ restantes não responderam a pergunta. Assim, frente ao número de participantes que não respondeu a pergunta, optou-se por não usar estes dados na pesquisa e utilizar os dados relativos à frequência semanal de condução para estimar exposição. Em relação aos dias por semana que dirigem, 72\% dos participantes costumam dirigir entre 3 a 7 dias por semana, enquanto $28 \%$ raramente dirigiam.

Em relação às multas, $79 \%$ afirmaram não terem sido multados nos últimos 3 anos, $17 \%$ afirmaram terem recebido multa no mesmo período e $4 \%$ não responderam a pergunta. A infração «ultrapassar o limite de velocidade» foi a que mais motivou multas (45\%), seguida por «estacionar em local proibido» (26\%), «não colocar o cartão EstaR (cartão de estacionamento regulamentado)» (13\%), «passar o sinal vermelho» $(8 \%)$ e, ambas com $4 \%$ das ocorrências, «não usar o cinto de segurança»e «fazer conversão em local proibido».

Em relação aos acidentes, $26 \%$ dos participantes se envolveram em pelo menos um acidente ativo, ou seja, em um acidente em que o próprio motorista tenha atingido algum usuário da estrada/ rua ou obstáculo causando pequenos e/ou grandes danos materiais e pessoais, desses $73 \%$ se envolveram em acidentes ativos causando apenas danos materiais. Quando questionados sobre o envolvimento em acidentes passivos $17 \%$ dos participantes declararam que se envolveram em pelo menos um acidente desse tipo, ou seja, em que ele tenha sido atingido por algum outro usuário da estrada/rua e desses em $88 \%$ dos casos os acidentes causaram apenas danos materiais.

\subsection{Instrumentos}

Foram utilizados dois instrumentos. O primeiro instrumento foi a Escala Family Climate for Road Safety (FCRS) desenvolvida por Taubman-Ben-Ari e Katz-Ben-Ami (2013), a qual avalia a percepção de jovens condutores quanto aos valores, prioridades, e as práticas dos pais e da família em relação à condução segura. No estudo de Taubman-Ben-Ari e Katz-Ben-Ami (2013), a Escala Family Climate for Road Safety (FCRS) foi correlacionada com a escala Perception of Parents Scale (Pops), proposta por Grolnick, Ryan e Deci (1991), com o Family Assessment Device proposta por Epstein, Baldwin e Bishop (1983), com o Family Adaptability and Cohesion Evaluation Scales III (Face III) proposta por Olson (1986), e o The Multidimensional Driving Style Inventory (MDSI) proposta por Taubman-Ben-Ari, Mikulincer e Gillath (2004). Além da validação da Escala FCRS, o estudo apresentou a relevância do clima familiar para a segurança no trânsito.

Inicialmente a escala foi traduzida e adaptada para o português através do procedimento da backtranslation, no qual o instrumento original é traduzido para o português por uma pessoa bilíngüe, a versão em português é traduzida para o inglês por outra pessoa bilíngüe e as duas versões em inglês são comparadas para verificar sua equivalência por um terceiro juiz fluente no idioma original, no caso o inglês. A versão brasileira da escala será chamada de Escala Clima Familiar para Segurança no Trânsito.

A Escala FCRS é composta por cinquenta e quatro perguntas, distribuídas em sete subescalas: Modelagem, Feedback, Comunicação, Monitoramento, Falta de Compromisso com a Segurança e Mensagem (Taubman-Ben-Ari \& Katz-Ben-Ami, 2013). Onze questões avaliam Modelagem: o modelo que os pais oferecem aos seus filhos por seus próprios modos de condução e atitude para com as leis de trânsito (alfa de Cronbach=0,87). Há cinco questões que avaliam Feedback: feedback positivo dos pais e incentivo aos filhos de atitudes positivas durante a condução (alfa de Cronbach=0,91). Há nove questões que avaliam Comunicação: comunicação aberta e direta entre pais e filhos, em relação ao seu comportamento durante a condução do veículo e suas tomadas de decisões (alfa de Cronbach=0,83). Há sete questões para Monitoramento: supervisão e acompanhamento dos pais aos jovens condutores (alfa de Cronbach=0,83). Há oito questões que avaliam a Falta de Compromisso com a Segurança: onde avalia a tendência da família em não investir tempo na direção segura, ignorar a condução de risco do jovem condutor, prestando atenção apenas no caso de acidentes no 
trânsito (alfa de Cronbach=0,71). Há oito questões que avaliam Mensagens: mensagens verbais claras dos pais com os filhos e a certeza de que seus filhos compreenderam a mensagem (alfa de Cronbach=0,83). Finalmente, há seis questões que avaliam Limites: apresentação pelos pais de um conjunto sistemático de regras e limites claros sobre o comportamento dos filhos e discipliná-los quanto as infrações de trânsito (alfa de Cronbach=0,74) (Taubman-Ben-Ari \& Katz-Ben-Ami, 2013). As questões que compõe cada subescala estão indicadas nas Tabelas 1, 2, 3 e 4. As respostas são em escala likert de cinco pontos, que vão de nunca para sempre. Destaca-se que alguns itens da escala original devem ser invertidos para análise $(11,15,23,24,31,37,42,47$ e 52), esse processo também ocorreu no momento da análise dos dados da versão brasileira da escala.

O segundo instrumento é um questionário de dados sociodemográficos. Este questionário tem como intuito identificar o perfil dos participantes e possui questões sobre idade, sexo, tempo que dirige com Carteira Nacional de Habilitação, tempo que dirigiu sem Carteira Nacional de Habilitação, qual a categoria de habilitação, com quem reside, com quem aprendeu a dirigir, se recebeu multa de trânsito nos últimos 3 anos e se esteve envolvido em acidentes de trânsito.

\subsection{Procedimentos de coleta de dados}

Os dados foram coletados em sala de aula e as aplicações foram em grupo. Os participantes foram comunicados por meio de Termo de Consentimento Livre e Esclarecido a respeito da pesquisa e convidados a, livre e voluntariamente, participar preenchendo os questionários. O procedimento durou aproximadamente 15 minutos.

\subsection{Procedimentos de análise de dados}

Foram realizadas análises estatísticas descritivas buscando identificar as características gerais dos participantes e do instrumento. Também foi realizado um estudo fatorial para verificar se a versão brasileira da escala possuía a mesma estrutura indicada no estudo original de Taubman-Ben-Ari e Katz-Ben-Ami (2013). A confiabilidade do instrumento foi estudada utilizando o alfa de Cronbach. Foram realizadas também Análises de Variancia (Anova).

\section{Resultados}

Inicialmente foram calculadas as médias e desvios padrão para os itens da escala. Os resultados podem ser observados nas últimas colunas das Tabelas 1, 2, 3 e 4. Em seguida, buscou-se verificar se o procedimento de análise fatorial era apropriado para os dados coletados. $\mathrm{O}$ valor de KaiserMeyer-Oklin foi 0,87, enquanto o teste de esfericidade de Bartlett foi estatisticamente significativo $(\mathrm{p}<0,001)$.

Conduziu-se uma análise fatorial com rotação Varimax, forçando a solução com sete subescalas, similar ao realizado no trabalho original (Taubman-Ben-Ari \& Katz-Ben-Ami, 2013). No entanto, ao analisar a distribuição dos itens pelas subescalas observou-se uma distribuição diferente em relação ao trabalho original, além disso, a solução não parecia teoricamente interpretável.

Ao fazer a análise do diagrama de sedimentação, verificou-se que a divisão em seis subescalas poderia ser mais adequada do que a divisão em sete subescalas. Foi então realizada outra análise fatorial, também com a rotação Varimax, forçando uma solução com apenas seis fatores, onde foi identificado que houve poucas mudanças em relação à análise com sete fatores, continuando difícil uma interpretação teórica adequada. Assim, realizou-se uma terceira análise fatorial, também com rotação Varimax, forçando uma solução com apenas cinco fatores que explicaram 44,75\% da variância com todos os cinco fatores com eigenvalues acima de 2 . Verificou-se que a divisão em cinco fatores poderia ser mais adequada do que a divisão em seis fatores, tendo em vista que a distribuição dos itens nos fatores ficou mais similar a do estudo original. A análise dos resultados sugeriu também, 
a aglutinação de quatro fatores do estudo original em dois fatores, correspondentes às subescalas Comunicação e Mensagem e Monitoramento e Limites.

Nas Tabelas 1, 2, 3 e 4 são apresentados os resultados da análise fatorial bem como as Variâncias Explicadas, as Médias e Desvios Padrão de cada subescala da versão brasileira da FCRS, conforme indicado no estudo de Taubman-Ben-Ari e Katz-Ben-Ami (2013). Um item era considerado relevante para inclusão em um fator quando sua carga fatorial era maior ou igual a 0,30. Deve-se destacar que dez itens obtiveram carga fatorial menor que 0,30 , nos fatores onde seria esperado que tivessem maior correlação. Assim, além da análise descrita acima, foi realizada uma análise de consistência interna das subescalas originadas dos cinco fatores por meio do alfa de Cronbach. Durante a análise, quando excluídos os dez itens, houve melhora dos alfas de Cronbach das subescalas e a sua inclusão em outras subescalas não tinha o efeito contrário. Os alfas de Cronbach de cada subescala podem ser encontrados na Tabela 5. Assim, na versão brasileira da FCRS, foi reduzido o número de itens de 54 para 44 itens.

Tabela 1. Descritivos e cargas fatoriais dos itens da Subescala Comunicação/Mensagem

\begin{tabular}{|c|c|c|c|}
\hline Itens & $\begin{array}{l}\text { Carga } \\
\text { Fatorial }\end{array}$ & Média $^{a}$ & DP \\
\hline $\begin{array}{l}\text { 4. Na minha família nós conversamos abertamente sobre erros no trânsito } \\
\text { ou acidentes que quase aconteceram, para que eu possa aprender com essas } \\
\text { situações. }\end{array}$ & 0,69 & 3,70 & 1,20 \\
\hline 5. Meus pais me dizem quando corro riscos desnecessários no trânsito. & 0,65 & 3,90 & 1,16 \\
\hline $\begin{array}{l}\text { 8. Na minha família falamos abertamente sobre qualquer coisa relacionada a } \\
\text { dirigir. }\end{array}$ & 0,62 & 4,21 & 1,04 \\
\hline $\begin{array}{l}\text { 46. Conversamos em casa sobre como prevenir ou evitar situações perigosas } \\
\text { no trânsito. }\end{array}$ & 0,62 & 3,38 & 1,38 \\
\hline $\begin{array}{l}\text { 2. Meus pais me ensinam como antecipar problemas em potencial no trânsito } \\
\text { antes que ocorram. }\end{array}$ & 0,55 & 3,78 & 1,16 \\
\hline 33. Meus pais conversam comigo sobre possíveis perigos no trânsito. & 0,52 & 3,82 & 1,23 \\
\hline 34. Eu participo na elaboração do contrato familiar sobre minha direção. & 0,52 & 2,90 & 1,45 \\
\hline $\begin{array}{l}\text { 51. Eu conto para os meus pais sobre as situações perigosas em que estive no } \\
\text { trânsito. }\end{array}$ & 0,52 & 3,64 & 1,29 \\
\hline 16. Meus pais me dizem quando acham que estou dirigindo de forma perigosa. & 0,50 & 4,13 & 1,11 \\
\hline 12. Meus pais realmente se importam se eu dirijo de forma segura. & 0,45 & 4,32 & 0,98 \\
\hline $\begin{array}{l}\text { 48. As expectativas de meus pais sobre mim enquanto dirijo são muito claras } \\
\text { para mim. }\end{array}$ & 0,43 & 3,97 & 0,10 \\
\hline 9. Eu sei como meus pais esperam que eu dirija. & 0,40 & 4,32 & 0,98 \\
\hline 38. Meus pais se interessam pelo modo com que dirijo. & 0,38 & 3,54 & 1,29 \\
\hline $\begin{array}{l}\text { 36. Posso falar livremente com meus pais sobre diferentes situações quando } \\
\text { se dirige. }\end{array}$ & 0,36 & 3,92 & 1,14 \\
\hline 28. Meus pais acreditam que dirigir de forma segura é muito importante. & $0,28^{\mathrm{b}}$ & 4,24 & 1,05 \\
\hline $\begin{array}{l}\text { 11. Meus pais não costumam falar muito sobre o modo como eu dirijo, mesmo } \\
\text { quando faço algo perigoso no trânsito. }\end{array}$ & $0,19^{\mathrm{b}}$ & 4,05 & 1,16 \\
\hline 37. Às vezes meus pais me encorajam a ignorar leis de trânsito. & $-0,16^{\mathrm{b}}$ & 4,26 & 1,13 \\
\hline Variância Explicada & $22,24 \%$ & & \\
\hline
\end{tabular}

${ }^{\text {a }}$ Escala variando de 1 a 5 pontos, sendo 1 para nunca e 5 para sempre.

${ }^{\mathrm{b}}$ Itens excluídos da versão brasileira 
Tabela 2. Descritivos e cargas fatoriais dos itens da Subescala Monitoramento/Limites

\begin{tabular}{|c|c|c|c|}
\hline Itens & Carga Fatorial & Média $^{\mathrm{a}}$ & DP \\
\hline $\begin{array}{l}\text { 18. Tenho que pedir permissão para os meus pais toda vez que quero sair de } \\
\text { carro. }\end{array}$ & 0,80 & 3,06 & 1,62 \\
\hline 13. Quando pego o carro, tenho que avisar meus pais aonde estou indo. & 0,79 & 3,36 & 1,47 \\
\hline $\begin{array}{l}\text { 21. Quando pego o carro, tenho que ligar para os meus pais e dizer se mudou } \\
\text { o lugar para onde estou indo. }\end{array}$ & 0,75 & 2,41 & 1,40 \\
\hline $\begin{array}{l}\text { 54. Quando pego o carro, tenho que avisar meus pais quando vou voltar para } \\
\text { casa. }\end{array}$ & 0,75 & 3,27 & 1,52 \\
\hline $\begin{array}{l}\text { 25. Quando pego o carro, tenho que avisar meus pais quem vai de carona, } \\
\text { onde quer que eu vá. }\end{array}$ & 0,71 & 2,17 & 1,30 \\
\hline $\begin{array}{l}\text { 7. Quando pego o carro, tenho que ligar para os meus pais e avisar se vou } \\
\text { me atrasar. }\end{array}$ & 0,59 & 2,46 & 1,40 \\
\hline $\begin{array}{l}\text { 19. Meus pais não me deixariam pegar o carro se eu fosse dirigir de forma } \\
\text { imprudente, mesmo se isso facilitasse algo para eles (ir a alguma loja, buscar } \\
\text { alguém). }\end{array}$ & 0,51 & 3,76 & 1,35 \\
\hline $\begin{array}{l}\text { 32. Se meus pais descobrissem que eu não estava dirigindo de forma } \\
\text { prudente, iriam impor limites na minha direção. }\end{array}$ & 0,51 & 3,63 & 1,32 \\
\hline $\begin{array}{l}\text { 43. Meus pais deixaram claro para mim que se eu não obedecesse às leis de } \\
\text { trânsito eles iriam restringir minha direção. }\end{array}$ & 0,43 & 3,16 & 1,51 \\
\hline $\begin{array}{l}\text { 27. Há um contrato não escrito entre meus pais e eu sobre minha direção } \\
\text { segura. }\end{array}$ & 0,36 & 2,80 & 1,43 \\
\hline 17. Minha família tem regras claras sobre dirigir com cuidado & $0,25^{\mathrm{b}}$ & 3,55 & 1,16 \\
\hline $\begin{array}{l}\text { 3. Meus pais se certificam de que eu não vou ficar brincando ou me distraindo } \\
\text { enquanto estou dirigindo. }\end{array}$ & $0,23^{\mathrm{b}}$ & 3,80 & 1,28 \\
\hline $\begin{array}{l}\text { 45. Meus pais me deixam pegar o carro com mais frequência quando sentem } \\
\text { que dirijo com cuidado. }\end{array}$ & $0,12^{\mathrm{b}}$ & 3,77 & 1,40 \\
\hline Variância Explicada & $8,62 \%$ & & \\
\hline
\end{tabular}

${ }^{\text {a }}$ Escala variando de 1 a 5 pontos, sendo 1 para nunca e 5 para sempre.

${ }^{\mathrm{b}}$ Itens excluídos da versão brasileira

Tabela 3. Descritivos e cargas fatoriais dos itens da Subescala Falta de Compromisso com a Segurança

\begin{tabular}{|c|c|c|c|}
\hline Itens & Carga Fatorial & Média $^{a}$ & DP \\
\hline 44. Meus pais ignoram quando dirijo perigosamente. & $-0,75$ & 1,61 & 1,14 \\
\hline $\begin{array}{l}\text { 40. Meus pais só prestam atenção se estou dirigindo de forma segura se } \\
\text { alguma coisa, como uma batida de carro, acontece. }\end{array}$ & $-0,59$ & 2,14 & 1,19 \\
\hline $\begin{array}{l}\text { 42. Meus pais estão dispostos a aceitar que eu chegue em casa atrasado } \\
\text { porque não quis correr com o carro. }\end{array}$ & $-0,58$ & 1,88 & 1,11 \\
\hline 29. Meus pais não perdem tempo me ensinando como dirigir de forma segura. & $-0,47$ & 2,40 & 1,31 \\
\hline $\begin{array}{l}\text { 52. Meus pais deixam claro que dirigir de forma segura é mais importante do } \\
\text { que chegar em algum lugar no horário. }\end{array}$ & $-0,34$ & 2,01 & 1,10 \\
\hline $\begin{array}{l}\text { 10. Na minha família é considerado um aborrecimento ter que obedecer } \\
\text { todas as regras do trânsito. }\end{array}$ & $-0,23^{b}$ & 1,88 & 0,99 \\
\hline $\begin{array}{l}\text { 22. Às vezes meus pais me dizem para acelerar quando o a luz do semáforo } \\
\text { fica amarela. }\end{array}$ & $-0,22^{b}$ & 1,93 & 1,12 \\
\hline $\begin{array}{l}\text { 41. As pessoas na minha família não gostam se alguém reclama que eles não } \\
\text { estão dirigindo de forma segura. }\end{array}$ & $-0,17^{b}$ & 2,77 & 1,28 \\
\hline Variância Explicada & $5,83 \%$ & & \\
\hline
\end{tabular}

${ }^{\text {a }}$ Escala variando de 1 a 5 pontos, sendo 1 para nunca e 5 para sempre.

${ }^{\mathrm{b}}$ Itens excluídos da versão brasileira 
Tabela 4. Descritivos e cargas fatoriais dos itens das Subescalas Modelagem e Feedback

\begin{tabular}{|c|c|c|c|c|}
\hline Subescala & Modelagem & Feedback & & \\
\hline Itens & $\begin{array}{c}\text { Carga } \\
\text { Fatorial } \\
\end{array}$ & $\begin{array}{c}\text { Carga } \\
\text { Fatorial }\end{array}$ & Média a & DP \\
\hline $\begin{array}{l}\text { 6. Meus pais servem de exemplo por obedecerem às leis de } \\
\text { trânsito. }\end{array}$ & 0,72 & & 3,71 & 1,07 \\
\hline $\begin{array}{l}\text { 20. Meus pais dirigem de forma segura mesmo quando estão } \\
\text { com pressa. }\end{array}$ & 0,62 & & 3,50 & 1,05 \\
\hline $\begin{array}{l}\text { 15. Meus pais só seguem as regras de direção segura para não } \\
\text { serem pegos. }\end{array}$ & 0,61 & & 3,86 & 1,13 \\
\hline $\begin{array}{l}\text { 50. Meus pais obedecem as leis de trânsito mesmo quando } \\
\text { estão cansados ou estressados. }\end{array}$ & 0,61 & & 3,52 & 1,06 \\
\hline 30. Meus pais servem de modelo para direção segura. & 0,57 & & 3,56 & 1,13 \\
\hline $\begin{array}{l}\text { 31. Meus pais conversam sobre direção segura, mas não } \\
\text { dirigem de forma tão segura. }\end{array}$ & 0,51 & & 3,65 & 1,19 \\
\hline $\begin{array}{l}\text { 23. Meus pais não gostam de admitir quando cometem algum } \\
\text { erro no trânsito. }\end{array}$ & 0,50 & & 3,29 & 1,25 \\
\hline $\begin{array}{l}\text { 24. Meus pais não são muito engajados com a questão da } \\
\text { direção segura }\end{array}$ & 0,49 & & 3,89 & 1,08 \\
\hline $\begin{array}{l}\text { 1. Meus pais planejam seu tempo tão bem que não ficam } \\
\text { pressionados pelo horário quando estão dirigindo. }\end{array}$ & 0,40 & & 3,04 & 0,98 \\
\hline $\begin{array}{l}\text { 39. Meus pais encaram cada violação de trânsito seriamente, } \\
\text { mesmo quando não resultou em um acidente. }\end{array}$ & 0,30 & & 3,49 & 1,28 \\
\hline $\begin{array}{l}\text { 47. Meus pais me dizem como dirigir com cuidado mesmo } \\
\text { quando eles não são motoristas cuidadosos. }\end{array}$ & $0,26^{\mathrm{b}}$ & & 2,75 & 1,36 \\
\hline $\begin{array}{l}\text { 49. Tenho feedback positivo dos meus pais quando eles me } \\
\text { veem dirigindo com cuidado. }\end{array}$ & & 0,77 & 3,64 & 1,27 \\
\hline $\begin{array}{l}\text { 53. Sinto que meus pais se orgulham de mim quando dirijo de } \\
\text { forma segura. }\end{array}$ & & 0,77 & 3,79 & 1,19 \\
\hline $\begin{array}{l}\text { 35. Meus pais me encorajam e aplaudem quando veem que } \\
\text { faço questão de dirigir com cuidado. }\end{array}$ & & 0,76 & 3,05 & 1,36 \\
\hline 26. Meus pais me cumprimentam por dirigir de forma segura. & & 0,75 & 3,04 & 1,33 \\
\hline $\begin{array}{l}\text { 14. Meus pais me elogiam quando dirijo de forma segura e } \\
\text { cuidadosa. }\end{array}$ & & 0,72 & 3,26 & 1,38 \\
\hline Variância Explicada & $4,87 \%$ & $4,42 \%$ & & \\
\hline
\end{tabular}

${ }^{a}$ Escala variando de 1 a 5 pontos, sendo 1 para nunca e 5 para sempre.

${ }^{\mathrm{b}}$ Itens excluídos da versão brasileira

Na Tabela 5, também encontram-se as informações referentes a Média e o Desvio Padrão das subescalas. A média mais alta é na subescala Comunicação/Mensagem que refere-se à comunicação aberta e direta entre pais e filhos, em relação ao seu comportamento durante a condução do veículo e tomada de decisão, além de mensagens verbais claras dos pais para os filhos e a certeza de que os filhos compreenderam essas mensagens. E, a subescala com menor média é Falta de Compromisso com a Segurança, que refere-se a tendência da família em não investir tempo na direção segura, ignorar a condução de risco do jovem condutor, prestando atenção apenas no caso de acidentes no trânsito (Taubman-Ben-Ari \& Katz-Ben-Ami, 2013). A média baixa nesta subescala, significa que os 
filhos percebem que seus pais se preocupam com a segurança no trânsito.

Tabela 5. Médias, Desvios Padrão e Alfas de Cronbach das subescalas da Escala Clima Familiar para Segurança no Trânsito

\begin{tabular}{lccc}
\hline \multicolumn{1}{c}{ Subescalas } & Média $^{\mathbf{a}}$ & DP & $\begin{array}{c}\text { Alpha de } \\
\text { Cronbach }\end{array}$ \\
\hline Comunicação/ Mensagem & 3,88 & 1,16 & 0,87 \\
Monitoramento/Limites & 3,17 & 1,39 & 0,87 \\
Falta de Compromisso com a Segurança & 2,08 & 1,15 & 0,70 \\
Modelagem & 3,48 & 1,14 & 0,79 \\
Feedback & 3,36 & 1,31 & 0,80 \\
\hline
\end{tabular}

${ }^{\text {a }}$ Escala variando de 1 a 5 pontos, sendo 1 para nunca e 5 para sempre.

Similarmente ao estudo original de Taubman-Ben-Ari e Katz-Ben-Ami (2013) foram realizadas correlações de Pearson entre as subescalas (Tabela 6). Encontrou-se correlações significativas positivas entre a subescala Comunicação/Mensagem e as subescalas, Modelagem e Feedback, ambas acima de 0,50. Assim, filhos que percebem mensagens abertas, diretas e claras dos pais, também percebem modelos positivos frente ao respeito com as leis de trânsito e incentivo à postura positiva dos filhos durante a direção. A análise encontrou também correlações negativas entre as subescalas Comunicação/Mensagem e Modelagem com Falta de Compromisso com a Segurança indicando que os filhos que percebem que os pais buscam uma conversa aberta, direta e clara em relação a uma condução segura e percebem neles um modelo positivo de segurança no trânsito, percebem, também, que não há nesses pais falta de compromisso com a segurança.

Tabela 6. Correlações de Pearson entre as subescalas da Escala Clima Familiar para Segurança no Trânsito

\begin{tabular}{lcccc}
\hline \multicolumn{1}{c}{ Subescalas } & $\begin{array}{c}\text { Comunicação/ } \\
\text { Mensagem }\end{array}$ & $\begin{array}{c}\text { Monitoramento/ } \\
\text { Limites }\end{array}$ & $\begin{array}{c}\text { Falta de } \\
\text { Compromisso com a } \\
\text { Segurança }\end{array}$ & Modelagem \\
\hline Comunicação/ Mensagem & - & - & - & - \\
Monitoramento/Limites & $0,48^{*}$ & - & - & - \\
$\begin{array}{l}\text { Falta de Compromisso com } \\
\text { a Segurança }\end{array}$ & $-0,53^{*}$ & $-0,26^{*}$ & - & - \\
Modelagem & $0,50^{*}$ & $0,22^{*}$ & $-0,49^{*}$ & - \\
Feedback & $0,51^{*}$ & $0,42^{*}$ & $0,24^{*}$ & $0,33^{*}$ \\
\hline
\end{tabular}

$* \mathrm{p}<.001$.

Foi realizada uma análise de variância, entre as 5 subescalas conforme o sexo dos participantes. Foram encontradas diferenças significativas nas subescalas Monitoramento/ Limites $\left(\mathrm{F}_{(1,418)}=5,72\right.$, $\mathrm{p}<0,05)$ e Feedback $\left(\mathrm{F}_{(1,418)}=4,75, \mathrm{p}<0,05\right)$. As mulheres, obtiveram maiores escores de Monitoramento/ Limites (Mulheres-Média=3,16, DP=0,91 e Homens-Média=2,92, DP=0,99) e também em Feedback, (Mulheres-Média=3,50, DP=1,02 e Homens-Média=3,27, DP=1,02).

Em seguida foi realizada uma análise de variância entre as 5 subescalas e com quem, o participante da pesquisa, aprendeu a dirigir (pai, mãe e Instrutor de Centro de Formação de Condutores). Estas opções foram divididas em dois grupos: Grupo1, composto pelo somatório entre o pai e a mãe $(\mathrm{N}=187)$ 
e Grupo 2 - Instrutor de Centro de Formação de Condutores (N=198). Não foram encontradas diferenças significativas.

Foi realizada, também, uma análise de variância entre as 5 subescalas e com quem os participantes residem. Foi feita uma divisão em dois grupos. O primeiro grupo era composto por jovens que moram com amigos, cônjuges, familiares ou sozinhos $(\mathrm{N}=181)$ e o segundo grupo composto por jovens que moram com pais, pai e mãe $(\mathrm{N}=239)$. Nesta configuração foi encontrada diferença significativa na subescala Monitoramento/Limites $\left(\mathrm{F}_{(1,358)}=5,85, \mathrm{p}<0,05\right)$. Os participantes que estavam no segundo grupo (pais, pai e mãe) tiveram um maior escore na subescala Monitoramento/Limites (Média=3,07, $\mathrm{DP}=0,93$ ) do que os participantes do primeiro grupo (Média=2,82, $\mathrm{DP}=0,99$ ).

\section{Discussão}

Taubman-Ben-Ari \& Katz-Ben-Ami (2013), apresentam a Escala Family Climate for Road Safety em sete subescalas, composta por 54 itens (Comunicação, Mensagens, Monitoramento, Limites, Falta de Compromisso com a Segurança, Feedback e Modelagem). Após analisar as variâncias explicadas de cada fator, e os alfas de Cronbach, optou-se pelo uso de cinco subescalas, onde foram aglutinadas as subescalas Comunicação/Mensagem e Monitoramento/Limites e mantidas as subescalas Falta de Compromisso com a Segurança, Modelagem e Feedback. A versão brasileira da Escala, intitulada como Escala Clima Familiar para Segurança no Trânsito ficou composta por 44 itens.

Quanto a consistência interna, os coeficientes alfa de Cronbach das subescalas Comunicação/ Mensagem $(0,87)$ e Monitoramento/Limites $(0,87)$ foram superiores aos valores obtidos por TaubmanBen-Ari \& Katz-Ben-Ami (2013). No estudo original os coeficientes de Alfa das subescalas foram: Comunicação $(0,83)$ / Mensagem $(0,83)$ e Monitoramento $(0,83)$ / Limites $(0,74)$. Na subescala Falta de Compromisso com a Segurança $(0,70)$ o coeficiente foi próximo ao do estudo original $(0,71)$ e nas subescalas Feedback $(0,80)$ e Modelagem $(0,79)$ os coeficientes foram inferiores aos valores obtidos por Taubman-Ben-Ari \& Katz-Ben-Ami (2013). Apesar destas últimas subescalas terem índices de confiabilidade abaixo daqueles do estudo original, foram escores acima de 0,70, o que faz com que possa ser considerada aceitável a consistência interna da adaptação Brasileira da Escala Clima Familiar para Segurança no Trânsito. Também é importante destacar que nesse estudo, a diferença do original (Taubman-Ben-Ari \& Katz-Ben-Ami, 2013), o primeiro fator foi responsável por quase 50\% da variância explicada, isso é um aspecto a ser investigado nos próximos estudos.

As médias das subescalas foram próximas às da amostra original. Comunicação/Mensagem $(M=3,88)$ versus Comunicação $(M=3,56)$ e Mensagem $(M=4,41)$ do estudo original. Monitoramento/ Limites $(M=3,17)$ versus Monitoramento $(M=3,04)$ e Limites $(M=3,23)$. Falta de Compromisso com a Segurança $(\mathrm{M}=2,08)$ versus $(\mathrm{M}=1,99)$, Modelagem $(\mathrm{M}=3,48)$ contra $(\mathrm{M}=3,67)$ e Feedback $(\mathrm{M}=3,36)$ versus $(\mathrm{M}=3,43)$ do estudo original.

Deve-se destacar que foi realizada uma análise de variância, entre as 5 subescalas e o sexo dos participantes onde foram encontradas diferença significativas nas subescalas Monitoramento/ Limites e Feedback. Nestas subescalas as mulheres, tiveram maiores escores do que os homens, assim como no estudo original de Taubman-Ben-Ari e Katz-Ben-Ami (2013). Estes resultados sugerem que as mulheres percebem mais feedback positivo dos pais e incentivo às atitudes positivas durante a sua condução e percebem mais um conjunto sistemático de regras e limites claros sobre o seu comportamento no trânsito e a tentativa de discipliná-las quanto as infrações de trânsito, corroborando com os achados de Taubman-Ben-Ari \& Katz-Ben-Ami (2013).

$\mathrm{Na}$ amostra deste estudo $44,8 \%$ aprenderam a dirigir com o pai ou com a mãe, 47,4\% com instrutor de centro de formação de condutor. Ao realizar uma análise entre as cinco subescalas e com quem aprendeu a dirigir, não foram encontradas diferenças significativas. Uma hipótese para este resultado é que conforme Braconnier e Marcelli (2000), a família influencia na educação, socialização, cuidados, transmissão de crenças e valores e no bem estar de seus componentes, assim, os valores transmitidos antes do início da prática de condução dos jovens, interferem na formação do jovem 
condutor, mais do que a formação prática propriamente dita.

Os itens da subescala Comunicação/Mensagem possuem perguntas como «Na minha família nós conversamos abertamente sobre erros no trânsito ou acidentes que quase aconteceram, para que eu possa aprender com essas situações», assim um escore alto indica um clima familiar mais seguro. Por outro lado os itens da subescala Falta de Compromisso com a Segurança, possuem perguntas como: «Meus pais só prestam atenção se estou dirigindo de forma segura se alguma coisa, como uma batida de carro acontece», onde um escore baixo indica um clima familiar mais preocupado com a segurança no trânsito. Assim, conforme dito anteriormente os filhos perceberem que os pais buscam uma conversa aberta, direta e clara em relação a uma condução segura, percebendo uma preocupação destes nos temas condução segura versus condução de risco.

Em uma última análise, foi encontrada diferença significativa na subescala Monitoramento/ Limites dentre os participantes que residiam com um dos pais, ou com ambos, dos participantes que residiam com familiares, amigos, cônjuge ou sozinhos. Este dado sugere que aqueles percebem, em seu convívio com os pais, uma supervisão e acompanhamento maior desses, além de mais regras e limites sobre o comportamento no trânsito do que os que deixam a casa paterna/materna.

\section{Limitações do estudo.}

Estudos futuros deveriam ampliar o poder de generalização do presente trabalho, já que a amostra, apesar de numericamente adequada para a validação do instrumento, não é representativa da população do Brasil.

\section{Considerações Finais}

Os dados mostram que a versão brasileira da Escala Clima Familiar para Segurança no Trânsito apresentou resultados adequados e pode ser utilizada em estudos futuros que queiram verificar o impacto do clima familiar no estilo de condução, ou mesmo na formação do jovem condutor.

\section{Referências}

Baumrind, D. (1966). Effects of Authoritative Parental Control on Child Behavior. Child Development, 37(4), 887-907.

Beck, K, Shattuck, T., \& Raleigh, R. (2001). Parental predictors of teen driving risk. American Journal of Heath Behavior, 25(1), 10-20.

Bianchi, A., \& Summala, H. (2004). The genetics of driving behavior: Parents' driving style predicts their children's driving style. Accident Analysis and Prevention, 36, 655-659. doi:10.1016/ S0001-4575(03)00087-3

Bowen, M. (1978). Family therapy in clinical practice. Nueva York, Londres: Jason Aronson.

Braconnier, A., \& Marcelli, D. (2000). As mil faces da adolescência. Lisboa: Climepsi.

Brasil. (1990). Estatuto da Criança e do Adolescente - Lei no 8.069/90. São Paulo: Atlas.

Cardoso, L. (2009). Práticas parentais e comportamento do condutor. (Trabalho de Conclusão de Curso. Graduação em Psicologia). Universidade Federal do Paraná, Brasil.

Costa, F. T., Teixeira, M. A. P., \& Gomes, W. B. (2000). Responsividade e exigência: duas escalas para avaliar estilos parentais. Psicologia: Reflexão e Crítica, 13(3), 465-473.

Curry, A., Corinne, P. A., \& Cara, H. (2015). Effectiveness of parent-focused interventions to increase teen driver safety: A critical review. Journal of Adolescent Health, 57, 6-14. doi:10.1016/j. jadohealth.2015.01.003.

Darling, N., \& Steinberg, L. (1993). Parenting style in context: An integrative model.

Psychological Bulletin, 113, 487-496. doi: 10.1037/0033-2909.113.3.487 
Departamento de Trânsito do Paraná. (2010). Anuário Estatístico 2010. Curitiba: Governo do Estado do Paraná.

Ehsani, J., Simons-Morton, B., Xie, Y., Klauer, S., \& Albert, P. (2014). The association between kinematic risky driving among parents and their teenage children: Moderation by shared personality characteristics. Accident Analysis and Prevention, 69, 56-61. doi:10.1016/j. aap.2014.03.015

Elander, J., West, R., \& French, D. (1993). Behavioral correlates of individual differences in roadtraffic crash risk: An examination of methods and findings. Psychological Bulletin, 113, 279-294.

Epstein, N. B., Baldwin, L. M., \& Bishop, D. S. (1983). The McMaster family assessment device. Journal of Marital and Family Therapy, 9, 171-180. doi: 10.1111/j.1752-0606.1983.tb01497.x

Goodwin, A., Foss, R., Margolis, L., \& Harrell, S. (2014). Parent comments and instruction during the first four months of supervised driving: An opportunity missed? Accident Analysis and Prevention, 69, 15-22. doi:10.1016/j.aap.2014.02.015

Grolnick, W. S., Ryan, R. M., \& Deci, E. L. (1991). The inner resources for school achievement: Motivational mediators of children's perceptions of their parents. Journal of Educational Psychology, 83, 508-517. doi:10.1037/0022-0663.83.4.508

Maccoby, E., \& Martin, J. A. (1983). Socialization in the context of the family parent child interaction. In P. H. Mussen (Ed.), \& E. M. Hetherington (Vol. Ed.), Socialization, personality, and social development (pp. 1-101). New York: Wiley.

Mayhew, D., Simpson, H., \& Pak, A. (2003). Changes in collision rates among novice drivers during the first months of driving. Accident Analysis and Prevention, 35, 683-691. doi:10.1016/S00014575(02)00047-7

Ministério da Saúde. (2013). Informações de saúde: estatísticas vitais. Brasília: Departamento de Informática do Sistema Único de Saúde.

Morton, G., \& Hartos, J. (2003). How well do parents manage young driver crash risks? Journal of Safety Research, 34, 91-97. doi:10.1016/S0022-4375(02)00085-3

Newman, K., Harrison, L., Dashiff, C., \& Davies, S. (2008). Relações entre modelos de pais e comportamentos de risco na saúde do adolescente: Uma revisão integrativa da literatura. Revista Latino-Americana de Enfermagem, 16(1), 142-150.

Olson, D. H. (1986). Circumplex model VII: Validation studies and Faces. Family Process, 25, 337351.

Olson, D. H., Partner, J., \& Lavee, Y. (1985). Faces III. Family Social Science. St. Paul: University of Minnesota.

OMS, Fnuap, \& Unicef. (1989). Saúde Reprodutiva dos Adolescentes. Disponível em: http:// bvsms. saude.gov.br/bvs/publicacoes/cd03 11.pdf

Parker, B., Watson, B., King, M., \& Hyde, M. (2014). Young novice drivers and the risky behaviours of parents and friends during the Provisional (intermediate) licence phase: A brief report, University. Accident Analysis and Prevention, 69, 51-55. doi:10.1016/j.aap.2013.11.016

Prato, C., Toledo, T., Lotan, T., \& Taubman-Ben-Ari (2010). Modeling the behavior of novice young drivers during the first year after licensure. Accident Analysis and Prevention, 42, 480-486. doi:10.1016/j.aap.2009.09.011

Scott-Parker, B., Watson, B., King, M. \& Hyde, M. (2012) They're lunatics on the road: Exploring the normative influences of parents, friends, and police on young novices' risky driving decisions. Safety Science, 50, 1917-1928. doi:10.1016/j.ssci.2012.05.014

Schmidt, B., Morrongiello, R., \& Colwell, S. (2014). Evaluating a model linking assessed parent factors to four domains of youth risky driving. Accident Analysis and Prevention, 69, 40-50. doi:10.1016/j.aap.2013.08.028

Seligman, M., \& Darling, R. (1997). Ordinary families special children. Nueva York: Guilford Press.

Simons-Morton, B., \& Quimet, M. (2006). Parent involvement in novice teen driving: A review of the literature. Injury Prevention, 12, 130-137. doi: 10.1136/ip.2006.011569 
Taubman-Ben-Ari, O. (2015). Parents' perceptions of the family climate for road safety. Accident Analysis and Prevention, 74, 157-161. doi:10.1016/j.aap.2014.10.023

Taubman-Ben-Ari, O., \& Miller, G. (2010). Driving styles among young novice drivers: The contribution of parental driving styles and personal characteristics. Accident Analysis and Prevention, 42, 558-570. doi:10.1016/j.aap.2009.09.024

Taubman-Ben-Ari, O. \& Katz-Ben-Ami, L. (2013). Family climate for road safety: A new concept and measure. Accident Analysis and Prevention, 54, 1-14. doi:10.1016/j.aap.2013.02.001

Taubman-Ben-Ari, O., Mikulincer, M., \& Gillath, O. (2005). From parents to children: Similarity in parents and offspring driving styles. Transportation Research, 8, 19-29. doi:10.1016/j. trf.2004.11.001

W. H. O. (2013). Global status report on road safety 2013: Supporting a decade of action. Berna: Departament of Violence \& Injury Prevention \& Disability (VIP). 